\title{
A transição para sociedades sustentáveis: uma abordagem a partir de processos educadores
}

\section{A transition into sustainable societies: an approach from educative processes}

\section{La transición hacia sociedades sostenibles: un enfoque a partir de procesos educadores}

\author{
Rachel Andriollo Trovarelli ${ }^{1}$ \\ Vivian Battaini ${ }^{2}$ \\ Marcos Sorrentino ${ }^{3}$
}

\begin{abstract}
Resumo
Neste artigo, buscamos contribuir com a reflexão sobre intervenções educadoras em direção à transição para sociedades mais sustentáveis a partir da experiência do Laboratório de Educação Ambiental e Políticas Públicas Oca (ESALQ/USP) com a criação de um curso de especialização. Com a abordagem metodológica qualitativa inspirada na pesquisa-intervenção, realizamos a coleta, análise e sistematização de dados do período de construção do curso, entre janeiro de 2016 e fevereiro de 2017, por meio da análise documental e da observação participante. Com os resultados obtidos, refletimos sobre o processo de construção participativa do curso, bem como enunciamos os principais desafios e aprendizados no tocante aos recursos, processos, relações e identidade na formação da equipe pedagógica. Ao final do artigo, apontamos algumas questões que nos parecem relevantes para pensar a continuidade de processos educadores ambientalistas como este, no contexto da universidade pública.
\end{abstract}

Palavras-chave: Educação ambiental. Transição. Sociedades sustentáveis. Pesquisa-intervenção. Universidade.

\begin{abstract}
In this article we seek to contribute to the reflection of educational interventions towards the transition into more sustainable societies. It was based on the experience of a specialization course creation inside the Laboratory of Environmental Education and Public Policy - Oca (ESALQ / USP). With the qualitative methodological approach inspired by the intervention research, we performed the collection, analysis, and systematization of data through documentary analysis and participant observation. This data was collected in the course construction period (between January 2016 and February 2017). With the results obtained we reflect on the process of participatory construction as well as the main challenges and learning regarding resources, processes, relationships, and identity in the formation of the pedagogical team. At the end of the article we point out some points for reflexion that seem relevant for the continuity of environmentalist educational processes, in the context of the public university.
\end{abstract}

Keywords: Environmental education. Transition. Sustainable societies. Intervention research. University.

\section{Resumen}

En este artículo, buscamos contribuir para la reflexión sobre intervenciones educativas hacia la transición para sociedades más sostenibles a partir de la experiencia del Laboratorio de Educación Ambiental y Política Públicas Oca (ESALQ / USP) con la creación de un curso de especialización. Con el enfoque metodológico cualitativo inspirado en la investigación-intervención, realizamos la recolección, análisis y sistematización de datos del período de construcción del curso, entre enero de 2016 y febrero de 2017, por medio del análisis documental y de la observación participante. Con los resultados obtenidos, reflexionamos sobre el proceso de construcción participativa del curso, así como enunciamos los principales desafíos y aprendizajes en cuanto a recursos, procesos,

\footnotetext{
${ }^{1}$ Mestre em ciências (ESALQ/CENA - USP), doutoranda em ciências (ESALQ/CENA - USP). racheltrovarelli@yahoo.com.br.

${ }^{2}$ Doutora em ciências (ESALQ/CENA - USP), pesquisadora colaboradora do Laboratório de Educação e Política Ambiental - Oca (ESALQ-USP).

${ }^{3}$ Doutor em educação (USP), professor livre-docente do departamento de Ciências Florestais (ESALQ-USP), coordenador do Laboratório de Educação e Política Ambiental - Oca (ESALQ-USP).
} 
relación e identidad en la formación del equipo pedagógico. Al final del artículo, señalamos algunas cuestiones que nos parecen relevantes para pensar la continuidad de procesos educadores ambientalistas como éste, en el contexto de la universidad pública.

Palabras clave: Educación Ambiental. Transición. Sociedades Sostenibles. Investigación de la intervención. Universidad.

\title{
1 Introdução
}

Diante da crise civilizatória (LEFF, 2002) contemporânea, é quase uníssona, no campo ambientalista, a necessidade de transição para outro modelo de sociedade. Apesar das diferentes visões entre correntes e tendências do campo (CASTELLS, 1999) tem ganhado espaço, nas últimas décadas, a busca por sociedades mais sustentáveis. Um marco nessa caminhada é o processo de construção e a publicação do Tratado de Educação Ambiental para Sociedades Sustentáveis e Responsabilidade Global, em 1992, durante o Fórum Global paralelo à Conferência das Nações Unidas sobre Desenvolvimento Sustentável, conhecida como Rio $92^{4}$.

Neste trabalho nos inspiramos no referido Tratado, além da prática cotidiana junto ao Laboratório de Educação e Política Ambiental, Oca, da Escola de Agricultura Luiz de Queiroz (ESALQ / USP) e na conjuntura política nacional e global, na qual percebemos um rápido avanço do conservadorismo, especialmente na negação de políticas públicas de direitos humanos, sociais, ambientais e de descentralização econômica. Para além da conjuntura, este trabalho se ancora na utopia que vislumbra sociedades mais sustentáveis (LEFF, 2001; SORRENTINO; NASCIMENTO, 2010) e felizes, garantindo o desenvolvimento autônomo das sociedades. Além disso, se pauta numa concepção de educação que tem como busca principal a emancipação humana (BRANDÃO, 2013; SORRENTINO et al, 2013; RANCIÈRE, 2015). Uma educação que contribui para o encontro com sentidos existenciais mais profundos (SCHUMACHER, 1979; GARAUDY, 1981; KRISHNAMURTI, 1994; FREIRE, 1997; RUSSEL, 2012; MORIN, 2014) e para os seres se desenvolverem como seres únicos e singulares (BIESTA, 2013). Dessa forma:

\begin{abstract}
[...] a razão de ser da educação não é apenas o ato de capacitar instrumentalmente produtores humanos através da transferência de conhecimentos consagrados e em nome de habilidades aproveitáveis. Antes disto, e para muito além disto, ela é um gesto de formar pessoas na inteireza de seu ser e de sua vocação de criar-se a si mesma e partilhar com os outros a construção responsável de seu próprio mundo social e vida cotidiana (BRANDÃO, 2013, p.80).
\end{abstract}

Consideramos, assim como Dallari (2002), a importância de reconhecer que estamos vivendo um período de transição, a mudança de um ciclo histórico. Isso significa perceber de qual local/tempo estamos saindo e para qual queremos ir e, para além disso, "que sejamos sujeitos ativos nesse processo histórico e possamos influir para que prevaleça a busca do bem da humanidade" (DALLARI, 2002, p.86).

$\mathrm{Na}$ perspectiva de transição para sociedades mais sustentáveis, ressaltamos a essencialidade de questionar velhos paradigmas, para que o novo possa emergir e se consolidar. Há diversas possibilidades de aprofundamento em torno desses temas, por exemplo: qual(is) a(s) diferença(s) conceituais e históricas entre desenvolvimento sustentável e sociedades sustentáveis? Qual(is) a(s) diferença(s) entre progresso e desenvolvimento econômico? Qual a relação entre sociedades sustentáveis e felicidade ou bem-estar social? Essas questões foram desenvolvidas nos trabalhos de Furtado (1974), Herculano (1992), Diegues (1992), Sorrentino

\footnotetext{
${ }^{4}$ Durante a Rio +20 houve a II Jornada do Tratado, na qual todos os princípios foram repactuados e mantidos.
} 
(1997), Viezzer (2004), Brandão, (2005), Meira e Sato (2005), Sato (2008), Boltanski e Chiapello (2009), Alves e Viezzer (2014) e são as principais referências neste trabalho.

Para além das diferenciações dos conceitos, destacamos o descontentamento da forma hegemônica de organização social e das relações entre seres humanos entre si e com os demais seres que habitam este planeta. Dessa forma, atuamos num processo de transição para sociedades diversas, plurais, com justiça socioambiental, nas palavras de Sorrentino (1997, p. 4), as características básicas de sociedades sustentáveis são "o avanço em direção a não exploração do ser humano pelo seu semelhante, à melhoria da qualidade de vida para todos e à não exploração ou degradação das condições de vida das demais espécies pela nossa".

Ao focar na transição para sociedades sustentáveis, reconhecemos

[...] a necessidade de romper com o que está estabelecido, dialogando com o instituído que permita transitar para transformar. Quando se fala de transição fica forte a necessidade e mudança na matriz energética e nas tecnologias, importantes, porém insuficientes, pois a transição exige processos educadores ambientalistas capazes de fomentar mudanças culturais que influenciem nas diversas áreas do existir; que formem sujeitos comprometidos com o Bem Comum e que atuem em distintas dimensões e temáticas na construção de "novos mundos possíveis" (BATTAINI; SORRENTINO, 2020, p.52).

Atuar nessa direção implica em pensar qual o nosso papel enquanto sujeitos ativos em um processo histórico. Nas palavras de Leff (2001),

\begin{abstract}
Nesse sentido, a educação ambiental adquire um sentido estratégico na condução do processo de transição para uma sociedade sustentável. (...) Dessa maneira, a aprendizagem é um processo de produção de significações e uma apropriação subjetiva de saberes. Nesse sentido, o processo educacional auxilia a formação de novos atores sociais, capazes de conduzir a transição para um futuro democrático e sustentável (LEFF, 2001, p.251, p.246).
\end{abstract}

Sorrentino et al. (2020) propõem uma atuação focada numa nova cultura da Terra, da terra e do território com o diálogo enquanto elemento central nos processos educadores ambientalistas e na criação, execução e avaliação de políticas públicas. Nessa perspectiva, um município que educa para a sustentabilidade tem seus diversos atores sociais envolvidos de corpo e alma com as transformações socioambientais, buscando rotas para a transição para sociedades sustentáveis. Esses sujeitos são pessoas comprometidas com a inclusão radical, fortalecimento dos direitos humanos e da cultura de procedimentos democráticos.

$\mathrm{Na}$ Oca temos trabalhado com três frentes sincrônicas de atuação: 1) a escala municipal; 2) os processos educadores; 3) o mergulho em si (SORRENTINO et al. 2013; OCA, 2016b). A reflexão em torno da proposta de escala municipal de atuação encontra consonância, ou até mesmo se inspira no conceito de municípios que educam para sustentabilidade (BRANDÃO, 2005; SORRENTINO et. al., 2020). Apoiamo-nos, também, no artigo 23 da Constituição Federal, que estabelece competências compartilhadas entre União, Estados, Distrito Federal e municípios. O município é a menor circunscrição administrativa autônoma do Estado, ou seja, a menor unidade político-administrativa no Brasil. Para além de um espaço natural, é também um lugar social, onde as relações culturais e sociais acontecem (BRANDÃO, 2005).

A atuação em processos educadores de escala municipal tem sido amadurecida por possibilitar um recorte territorial institucional, mas, também, por promover notórios aspectos identitários. Em geral, temos uma relação marcante com nossa própria história de vida que perpassa pelo local em que nascemos, crescemos e vivemos. Frequentemente, esse senso de identidade é municipal. No entanto, em megacidades como São Paulo, por exemplo, o bairro ou região do município também pode oferecer a institucionalidade (subprefeituras, por exemplo) e a identidade que revela um perfil, possíveis tribos (por exemplo, os moradores do bairro 
Liberdade, no município de São Paulo, com a valorização de características da cultura japonesa).

Segundo o Instituto Brasileiro de Geografia e Estatística (IBGE), há 5.570 municípios no país. Destes, $68,3 \%$ têm até 20 mil habitantes, enquanto 5,6\% têm até 100 mil habitantes (IBGE, 2018). Esses municípios abrigam $72 \%$ da população brasileira e correspondem a 73,9\% dos municípios. Torna-se relevante que a atuação educadora na transição para sociedades sustentáveis seja pensada a partir da escala local ou de territórios de convivencialidade que permitam um aprofundamento dos mapeamentos e diagnósticos (fatores abióticos e bióticos, sociais, institucionais, econômicos, culturais, políticos, as relações interpessoais, as utopias e afins) e dessa forma, o conhecer e reconhecer os desejos, desafios e potencialidades de cada contexto.

O segundo fator que nos tem parecido relevante é a formação de lideranças educadoras na transição para sociedades mais sustentáveis. Para isso, e em consonância com o papel da universidade pública de formação de profissionais comprometidos com o bem comum, temos buscado diferentes formatos de formação, dentro de uma concepção de educação pautada por cinco fundamentos: identidade, comunidade, diálogo, potência de ação e felicidade (SORRENTINO et al., 2013). E, mais recentemente, por doze componentes que temos considerado relevantes para os processos educadores: mapeamentos e diagnósticos; conjuntura e utopias; cardápio de conteúdos; mergulhar em si próprio; educomunicação; pesquisa intervenção; círculos de cultura; planejamento participativo incremental e articulado; registro, sistematização, monitoramento e avaliação; estudar, ler, aprender e pesquisar; e incidir em políticas públicas (OCA, 2016b) ${ }^{5}$.

Quanto ao terceiro ponto, um dos doze componentes é o mergulhar em si. Isso significa um processo continuado de autodesenvolvimento, alinhado com as utopias e desejos individuais que reverberam, dialogam e contribuem na proposição de estratégias para a construção de sociedades mais sustentáveis. Esse item envolve se autoconhecer, inclusive em termos corporais, emocionais e espirituais:

[...] Compreender a vida é compreender a nós mesmos; este é o princípio e o fim da educação. (...) A função da educação é criar entes humanos integrados e, por conseguinte, inteligentes. Podemos tirar diplomas e ser mecanicamente eficientes, sem ser inteligentes. A inteligência não é mera cultura intelectual (...). Inteligência é a capacidade de perceber o essencial, o que é; despertar essa capacidade, em si próprio e nos outros, eis em que se resume a educação (KRISHNAMURTI, 1994, p. 12-13).

Autores como Nepomucemo (2015), Sorrentino e Portugal (2016), Tassara e Ardans (2013), Alves e Sorrentino (2013), Andrews (2011), Russell (2012), Krishnamurti (1994), entre outros, nos ajudam a perceber que, se não há sinceridade com as utopias e desejos individuais relacionando-os com o Bem Comum, a ação educadora ambientalista não se sustenta a médio/longo prazo. Tal dificuldade emerge, especialmente, numa conjuntura hegemônica pautada pelo neoliberalismo, que, segundo Hardt e Negri (2014) produzem figuras de subjetividades caracterizadas como empobrecidas e paralisantes:

A hegemonia das finanças e dos bancos produziram o endividado, o controle das informações e das redes de comunicação criaram o mediatizado. O regime de segurança e o estado generalizado de exceção construíram a figura oprimida pelo medo

\footnotetext{
${ }^{5}$ Para se chegar em tais elementos, há um conjunto de referenciais bibliográficos que nos inspiram e podem ser aprofundados. No entanto, apesar da assertividade de se chegar em cinco fundamentos e doze componentes, há de se destacar a incrementabilidade de tais propostas. A Oca é um coletivo que se autocaracteriza como "nós somos movimento" (OCA, 2016a) e, portanto, a revisão e recomeço das premissas é uma prática quase cotidiana.
} 
e sequiosa de proteção: o securitizado. E a corrupção da democracia forjou uma figura estranha, despolitizada: o representado (HARDT; NEGRI, 2014 p. 21).

No entanto, sendo este um momento de transição, estão presentes a dialética e a contradição constante entre dedicar energia às propostas inovadoras e criativas que possibilitariam a transição e, por outro lado, a necessidade de atender aos procedimentos hegemônicos que, muitas vezes, atuam na direção contrária.

Nesse contexto de busca por respostas sobre como realizar de fato ensino, pesquisa, gestão e extensão, de forma viável, competente e comprometida com a construção de sociedades mais sustentáveis, nasce e amadurece, no Laboratório Oca, a proposta de realização de cursos de especialização.

Sendo assim, temos como objetivo deste artigo contribuir com a reflexão sobre intervenções educadoras em direção à transição para sociedades mais sustentáveis a partir da experiência da Oca, com a criação e execução do curso de especialização Educação Ambiental e Transição para Sociedades Sustentáveis. Como objetivos específicos, consideramos: 1) sistematizar dados do período de construção do curso, realizado entre janeiro de 2016 até a realização das primeiras aulas, em fevereiro de 2017, e 2) refletir sobre o processo de construção participativa do curso.

\section{Metodologia}

Para o presente estudo, optamos por utilizar a metodologia qualitativa (MINAYO, 2001), inspirada em autores como Becker (1994) que sugere que o método não é camisa de força, mas, sim, idiossincrático. Outra importante influência remete à Teoria da Complexidade de Morin (1996, p. 335), ao considerar que "o método, para ser estabelecido, precisa de estratégia, iniciativa, invenção e arte".

A pesquisa-intervenção tem como pressuposto uma ação intencional no território, a qual possibilita o desenvolvimento de estudos, a promoção de reflexões e aprendizados: "A pesquisa-intervenção consiste em uma tendência das pesquisas participativas que busca investigar a vida de coletividades na sua diversidade qualitativa, assumindo uma intervenção de caráter socioanalítico (ROCHA; AGUIAR, 2003, p.66). Na presente investigação, a influência da perspectiva da pesquisa-intervenção se materializou em processos educadores com a equipe envolvida na construção pedagógica e administrativa do curso.

As técnicas de coleta de dados foram: análise de documentos institucionais (Projeto Político Pedagógico da Oca, materiais sobre o processo de elaboração do curso de especialização, roteiros de monitoramento e avaliação da Secretaria de Cursos, formulário de interesse em participar da equipe da Especialização e atas de reuniões), e observação participante em reuniões da equipe pedagógica do curso de especialização e do laboratório. A seguir, uma síntese da metodologia utilizada no Quadro 1.

Quadro 1 - Síntese da metodologia utilizada na pesquisa

\begin{tabular}{|c|c|c|}
\hline Inspiração metodológica & Técnicas de coleta de dados & Análise dos dados \\
\hline Pesquisa-intervenção & Análise documental de & Triangulação de técnicas \\
\hline & diferentes fontes & e fontes \\
\hline & Observação participante & \\
\hline
\end{tabular}

Para análise dos dados foi utilizada a triangulação das técnicas de coleta de dados (DENZIN; LINCOLN, 1994), sendo estes, incialmente, categorizados de acordo com a proposta 
de quadrimembração de organizações e grupos ${ }^{6}$. Tal abordagem sugere que o caminho de amadurecimento de grupos e instituições se dá pelo equilíbrio entre as quatro dimensões: (a) recursos, (b) processos, (c) relações e (d) identidade. No Quadro 2 há uma síntese das fases de desenvolvimento das organizações.

\begin{tabular}{|c|c|c|c|c|}
\hline & Pioneira & Estruturada & Integrada & Associativa \\
\hline Identidade & $\begin{array}{l}\text { - Identidade não é } \\
\text { definida } \\
\text { - O que importa é o ideal } \\
\text { do fundador/idealizador }\end{array}$ & $\begin{array}{l}\text {-Ideal esquecido ou } \\
\text { difuso } \\
\text {-Não compartilhada }\end{array}$ & $\begin{array}{l}\text { - Consciente } \\
\text { - Todos conhecem } \\
\text { - Construída a partir } \\
\text { do ideal e do histórico }\end{array}$ & $\begin{array}{l}\text { - Atenção consciente } \\
\text { à própria identidade } \\
\text { que é reconhecida em } \\
\text { seu ambiente social }\end{array}$ \\
\hline Relações & $\begin{array}{l}\text { - Pouca hierarquia } \\
\text { - Informais } \\
\text { - Espontânea } \\
\text { - Confiança }\end{array}$ & $\begin{array}{l}\text { - Formais } \\
\text { - Papéis e níveis } \\
\text { hierárquicos bem } \\
\text { definidos } \\
\text { - Sem espontaneidade } \\
\text { - formação de } \\
\text { "panelas", grupismos }\end{array}$ & $\begin{array}{l}\text { - diálogo aberto } \\
\text { - participação ativa } \\
\text { - Há feedbacks e } \\
\text { avaliação } \\
\text { - aprendizado } \\
\text { constante } \\
\text { - comunicação fluida }\end{array}$ & $\begin{array}{l}\text { - Em cadeias / } \\
\text { associação } \\
\text { - Clientes integrados } \\
\text { no sistema }\end{array}$ \\
\hline Processos & $\begin{array}{l}\text { - Flexíveis } \\
\text { - Não definidos } \\
\text { - Não há papéis definidos } \\
\text { - Improviso } \\
\text { - Descuido com controles }\end{array}$ & $\begin{array}{l}\text { - Sistematizados } \\
\text { - Há políticas } \\
\text { - Definição de metas } \\
\text { - Divisão de tarefas } \\
\text { - Controles rígidos } \\
\text { - Centralização }\end{array}$ & $\begin{array}{l}\text { - ágeis } \\
\text { - definidos em razão } \\
\text { das necessidades } \\
\text { - orientados para } \\
\text { atender expectativas } \\
\text { dos clientes }\end{array}$ & $\begin{array}{l}\text { - Fluidos, } \\
\text { determinados pelas } \\
\text { demandas }\end{array}$ \\
\hline Recursos & $\begin{array}{l}\text {-Escassos ou inexistentes } \\
\text { - Captados através de } \\
\text { doações ou investimentos } \\
\text { pessoais }\end{array}$ & $\begin{array}{l}\text { - Investimento em } \\
\text { necessidades } \\
\text { materiais como: } \\
\text { Tecnologia, } \\
\text { ampliação da sede, } \\
\text { compra de novos } \\
\text { equipamentos } \\
\end{array}$ & $\begin{array}{l}\text { - Investimento nas } \\
\text { pessoas (técnico e } \\
\text { comportamental) } \\
\text { - Uso mais consciente } \\
\text { dos recursos naturais }\end{array}$ & $\begin{array}{l}\text { - Direcionados para a } \\
\text { eficácia de processos } \\
\text { - Uso racional }\end{array}$ \\
\hline
\end{tabular}

Fonte: adaptado de Germinar (2015)

Em recursos está a base das organizações. Compreende recursos materiais, estruturais e financeiros. Em âmbito pessoal, relaciona-se com o aspecto da segurança do indivíduo. Já os processos envolvem os procedimentos organizacionais, os fluxos, os caminhos que são necessários para que o trabalho flua. $\mathrm{Na}$ dimensão pessoal, os processos estão ligados com a dedicação, o uso das competências técnicas, das habilidades no trabalho de forma realizadora. $\mathrm{O}$ campo das relações refere-se as relações interpessoais, envolvendo, por exemplo, a confiança nos membros da equipe, a solidariedade, o respeito, enfim, os valores que forem pactuados no coletivo, que contribuem para a manutenção de boas relações. Em nível pessoal, esse campo está relacionado aos sentimentos e afetividade. E, por fim, a dimensão da identidade, isso é, a missão, visão e valores do grupo, a cola que une em termos identitários, a filosofia da organização, as utopias comuns. No âmbito pessoal, relaciona-se com a biografia, a consciência do indivíduo (SCHAEFER; VOORS, 2000; GERMINAR, 2015).

No desenvolvimento das organizações, essa perspectiva sugere um processo que passa por quatro fases: pioneira, estruturada, integrada e associativa. Em cada uma delas a dinâmica entre essas quatro dimensões (recursos, processos, relações e identidades) têm características e desafios próprios, como resumido no Quadro 2.

\footnotetext{
${ }^{6}$ Perspectiva antroposófica a qual tivemos contato via Curso de Formação de Facilitadores Sociais - Germinar. Maiores informações: http://ecosocial.com.br/programa-germinar.
} 


\section{Resultados}

Nesta sessão, apresentamos os resultados desta pesquisa, iniciando com uma breve (3.1) descrição do processo de construção de curso para, na sequência (3.2), apresentar o detalhamento e análise do processo a partir da quadrimembração de organizações e finalizar (3.3) com uma análise da construção participativa do curso.

\subsection{Descrição do processo de construção inicial do curso}

A construção inicial do curso se refere ao período em que iniciamos os diálogos sobre os tramites institucionais para sua realização até o início do mesmo com a turma de estudantes, isso é, de janeiro de 2016 a fevereiro de 2017. Foi um momento de amadurecimento administrativo e pedagógico do projeto ${ }^{7}$.

O processo iniciou-se com a nossa participação (autores deste trabalho) como coordenadores $^{8}$. Nos primeiros meses do ano (2016), os trabalhos resumiam-se às questões institucionais de criação e aprovação do curso nas diferentes instâncias universitárias ${ }^{9}$, envolvendo a elaboração da documentação acadêmica e financeira. Para tanto, foi definido um escopo geral do curso em termos pedagógicos e administrativos.

Em seu escopo pedagógico, destacamos ser um curso presencial com encontros mensais, carga horária de 560 horas, ao longo de dois anos. A proposta pedagógica está organizada em torno de quatro eixos conceituais e transversais (intitulados educação ambiental; intervenção e conhecimento científico; utopia, conjuntura e espiritualidade; e políticas públicas de transição para sociedades sustentáveis) e o planejamento, execução e avaliação de um projeto de intervenção socioambientalista.

Dentre os desafios vividos naquele momento, destacamos o processo de aprender com o erro, a formação de parcerias, e os aprendizados no relacionamento com as instâncias institucionais.

Somamos a esse desafio o dilema de diálogo institucional, devido a, pelo menos, duas divergências de concepções pedagógicas entre a proposta do curso de especialização e a concepção hegemônica da universidade: (1) o curso traz uma concepção de educação que privilegia a transdisciplinaridade, porém o regimento da universidade para cursos de extensão exige a enunciação de suas disciplinas para aprovação; (2) a equipe se propunha a incrementar a construção do curso articuladamente com demais participantes do processo (professores, monitores, coordenadores, estudantes) e com os perfis, necessidade e desejos dos futuros estudantes. Tal opção está ancorada no planejamento incremental e articulado (OCA, 2016b; SORRENTINO; NASCIMENTO, 2010). No entanto, um ano antes do início do curso era necessário prever cada professor e sua respectiva carga horária de aulas, os conteúdos a serem ministrados, o formato de avaliação, entre outros.

Embora nossos esforços e expectativas fossem que o curso tivesse início em julho/2016, tais procedimentos de aprovação e aprendizados da equipe tornaram inviável essa possibilidade, e o início do curso foi postergado para fevereiro de 2017. Com a nova documentação em trâmite, a partir de julho/2016 foi fortalecido o processo de gestão e dado início ao processo de construção participativa das questões pedagógicas.

\footnotetext{
${ }^{7}$ Ressaltamos que a proposta do curso tem sido amadurecida há anos pelo Laboratório Oca com a realização de outros projetos e ações que promoveram desafios e aprendizados que se tornaram acúmulo para tal experiência. Como, por exemplo, um Curso de Especialização realizado em 2000/2001.

${ }^{8}$ No primeiro semestre de 2016, o trabalho foi fortalecido pela construção do curso de especialização Agroecologia e a Transição Educadora para Sociedades Sustentáveis, liderado por um estudante de graduação. Ambas as equipes caminharam juntas, visto que os desafios eram similares e havia poucas pessoas envolvidas.

${ }^{9}$ Departamento de Ciências Florestais, setor de Cultura e Extensão universitária da ESALQ, Prefeitura do campus Luiz de Queiroz - setor de convênios - e a Reitoria de Cultura e Extensão universitária da USP.
} 
Com relação à gestão, foi uma etapa na qual focamos na criação de procedimentos, métodos e técnicas de trabalho coletivo e individual. O foco do grupo era a criação de uma Secretaria de $\operatorname{Cursos}^{10}$ para o Laboratório Oca que pudesse, para além dos cursos de especialização, acolher outras iniciativas de formação de educadores em médio prazo. Para tanto, a equipe foi ampliada com a chegada de mais três profissionais voluntários. Nesse processo, foram marcantes três desafios: (1) o processo de captação de recursos e articulações institucionais; (2) criação e implementação de estratégias de comunicação e marketing para divulgar e vender o curso; (3) mapeamento de estudantes interessados para, posteriormente, iniciar o processo de inscrição e seleção dos estudantes.

$\mathrm{O}$ processo pedagógico se fortaleceu com as reuniões periódicas para construção participativa do curso, no segundo semestre de 2016. Naquele momento, outros interlocutores de dentro e fora do Laboratório Oca começaram a se aproximar e a participar ${ }^{11}$.

Um grande desafio vivido no âmbito pedagógico foi a construção e consolidação de um grupo, de acordos de trabalho, bem como de construção de identidade e de entendimento da proposta. Aqui, nasceram reflexões e diálogos profundos sobre o papel do Laboratório de Educação e Política Ambiental no cumprimento de suas atribuições relacionadas à pesquisa, ensino e extensão, e a necessidade/opção de realizar um curso pago na universidade pública.

Com a equipe formada, com os processos de gestão e ensino trilhados e a documentação institucional aprovada, abrimos as inscrições, via formulário, apresentando-se, aproximadamente, cem inscritos. Fizemos uma seleção de cinquenta estudantes, dos quais apenas dezesseis confirmaram a matrícula no período previsto. Fizemos uma segunda chamada com os demais estudantes da lista de espera. Ainda assim, poucos se matricularam. Novas vagas foram abertas e chegamos aos 31 estudantes inscritos em fevereiro de $2017^{12}$. Tal fato exigiu, novamente, uma reorganização estrutural e financeira no grupo, já que a previsão orçamentária contava com cinquenta participantes.

A turma matriculada foi formada por profissionais na maioria com graduação na área ambiental (ciências biológicas, gestão ambiental, geografia, entre outros), seguidos por participantes com formação em ciências humanas (comunicação social, letras, história, entre outras). A área de atuação mostrou-se variada entre setor público, terceiro setor e movimentos sociais e setor privado. A faixa etária predominante era entre 24 a 33 anos e $75 \%$ eram mulheres.

Ao início do curso, passamos a trabalhar com uma equipe de quatro pessoas no subgrupo, isso é, o núcleo animador, os responsáveis por catalisar os processos, sendo duas coordenadoras e dois monitores. Como equipe pedagógica expandida, aglutinamos mais oito profissionais dispostos a contribuir de diferentes formas.

Esse foi um breve resumo histórico sobre o período de construção inicial do curso. $\mathrm{Na}$ próxima sessão apresentamos uma análise focada nas dimensões de recursos, processos, relações e identidade.

\subsection{Detalhamento e análise do processo a partir da quadrimembração de organizações}

- Recursos: em termos de recursos, desde o início do projeto já havia algum aporte da universidade, do Laboratório Oca e do envolvimento voluntário de pessoas. O apoio da

\footnotetext{
${ }^{10}$ A ideia central é que a Secretaria de Cursos viabilize um processo de formação continuada, em Piracicaba, com cinco objetivos centrais: (a) fortalecer a universidade pública; (b) formar multiplicadores; (c) disseminar e construir conhecimentos na área socioambiental; (d) fortalecer a Oca; (e) fortalecer o Curso de Especialização em Educação Ambiental e Transição para Sociedades Sustentáveis.

11 Os procedimentos operacionais e pedagógicos dos dois cursos de especialização e outras iniciativas no Laboratório Oca começaram a caminhar de forma independente.

12 Após o início das aulas, mais duas estudantes se matricularam, totalizando 33 estudantes matriculados nessa turma.
} 
universidade se deu pela infraestrutura (espaço físico do laboratório, energia elétrica, banheiro, mesas, cadeiras, cozinha), materiais pedagógicos (datashow, lousas móveis), de consumo (materiais de escritório), recursos humanos (apoio da secretaria do departamento de Ciências Florestais, professores e coordenador geral do curso) e bolsas de estudos (um estudante de graduação e uma de pós-graduação).

O Laboratório Oca apoiou a estruturação do Curso com recursos para gastos diversos, tais como: remuneração de uma coordenadora do projeto, serviços gráficos, ajuda de custos para as pessoas voluntárias da equipe.

No período, buscamos captar recursos de inúmeras formas, como por exemplo, contratação de profissionais especializados, parcerias, convênios, patrocinadores. No entanto, sem um sucesso significativo que possibilitasse um salário aos integrantes da equipe que atuavam de forma voluntária. Essas tentativas também estavam num contexto de captar recursos para viabilizar um curso de menor custo ou gratuito aos estudantes. Trazemos mais reflexões sobre a relação da universidade pública e cursos pagos no item identidade.

Frente às dificuldades de captação de recursos, optamos pela tentativa de realizar cursos de curta duração ( 8 horas), visando aumentar a ajuda de custo aos voluntários e estruturar todo o processo organizacional, logístico e pedagógico para o curso de especialização. Assim, foram realizados dois cursos, no entanto, sem significativo ganho financeiro.

Para além da dificuldade enfrentada com relação aos recursos financeiros, houve o desafio de formação dos profissionais da equipe, visto que a maior parte deles, não tinha formação na sua área de atuação dentro do projeto. Dessa forma, aprendíamos ao realizar as tarefas. Por um lado, foi um rico processo de formação, por outro, exigia maior tempo de dedicação para a realização das atividades.

- Processos: em termos de processos, tudo foi construído ao caminhar, valorizando as experiências prévias de cada um dos envolvidos. Houve muitos momentos em que as reuniões do subgrupo focaram na construção de metas, esclarecimentos dos papeis e atribuições de cada pessoa no grupo, bem como na construção de acordos coletivos sobre o modus operandi. A partir daí, criamos uma série de procedimentos de trabalho tais como reuniões semanais, tabela de encaminhamentos, banco de dados e agenda semanal compartilhada.

Detalhando cada elemento procedimental, as reuniões semanais tinham duração de duas horas, com estrutura de 1) acolhimento e boas vindas; 2) informes; 3) pautas; 4) diálogos sobre as tarefas de cada um, sistematizadas na forma de uma tabela de encaminhamentos; 5) avaliação. Cada reunião era animada previamente, planejada e conduzida por uma das pessoas. Sempre foi feita uma ata de registro, compartilhada na semana que se seguia. O responsável pela ata era o próximo facilitador/animador da reunião na semana seguinte. Essas reuniões tinham um foco mais administrativo e operacional do que pedagógico.

Quanto à tabela de encaminhamentos, foi desenvolvida coletivamente uma tabela na qual foram listadas todas as tarefas a serem feitas, os responsáveis e, eventualmente, os prazos. Durante a semana cada um deveria atualizar tal planilha, que era disponibilizada na nuvem de dados digitais, via aplicativo Google Drive.

Também, foi criado um banco de dados coletivo, via aplicativo Google Drive, que possibilitou o trabalho simultâneo em diferentes computadores e disponibilizou os arquivos a todos os membros da equipe.

Concernente à agenda semanal coletiva, nesta estavam definidos os horários de trabalho, que foram preenchidos semanalmente. Foi feito o registro de qual atividade seria realizada e em qual período da semana. Tal procedimento contribuiu para dar visibilidade ao que todos estavam fazendo e facilitou a comunicação mais direta e assertiva sobre questões que envolviam mais de um membro da equipe. 
Vale destacar que, em alguns momentos, a criação de procedimentos foi desgastante para equipe, visto que era uma nova forma de trabalhar, mais estruturada. Vejamos a avaliação sobre as dificuldades do grupo, no ano de 2016, por uma das participantes do subgrupo: "não estamos familiarizados com as atividades demandadas e precisamos de tempo para aprender e descrever como fazer" (Roteiro de monitoramento. Subgrupo: Secretaria de Cursos, 2016).

Outra participante, avaliando as dificuldades, destacou a necessidade de "realizar tarefas e buscar caminhos que nunca havíamos trilhado antes (comunicação, documentação USP, financeiro etc)." (Roteiro de monitoramento. Subgrupo: Secretaria de Cursos, 2016).

No entanto, os procedimentos foram criados de forma participativa e processual, em inúmeras reuniões, valorizando a sinceridade de cada um dos envolvidos, com constantes avaliações e ajustes, sempre que necessário. Ações de cuidado do grupo foram muito importantes, fossem elas individualizadas ou coletivas, com foco em clarear situações que geraram desconfortos, celebrar cada conquista e no estar junto fortalecendo os vínculos e a confiança. Tais estratégias são aprofundadas no item relações.

O próprio objetivo do subgrupo, para 2016, enunciava a demanda por criação de procedimentos, especialmente no período que o grupo se identificava mais com a proposta de criação de uma Secretaria de Cursos:

1. Criar e executar um conjunto de procedimentos que viabilizem cursos oriundos de demandas internas e externas à Oca pautados em processos formativos de seus membros; 2. Viabilizar os cursos de especialização "Educação Ambiental e Transição para Sociedades Sustentáveis" e "Educação, Agroecologia e Reforma Agrária para a construção de Sociedades Sustentáveis" (Roteiro de monitoramento, Subgrupo: Secretaria de Cursos, 2016)

Outro aspecto importante envolveu o estudo e reflexão, em uma das reuniões, sobre autoanálise e autogestão, que é uma opção ideológica na Oca. Segundo Baremblit (2002, p. 17):

Esse processo de autoanálise das comunidades é simultâneo ao processo de autoorganização, em que a comunidade se articula, se institucionaliza, se organiza para construir dispositivos necessários para produzir, ela mesma, ou para conseguir recursos de que precisa para a manutenção e melhoramento de sua vida na terra

A partir daí, houve o amadurecimento, enquanto grupo, que todas essas técnicas ou ferramentas de procedimentos não funcionam se não houver a perspectiva emancipatória e de busca de sentidos existenciais no processo. Essas ferramentas podem ser tão opressoras ou autoritárias, quanto libertadoras e emancipatórias, dependendo da filosofia que se baseiam (DEMO, 1996).

- Relações: no âmbito das relações, é uma cultura no Laboratório Oca o cuidado com o outro, o acolhimento, o respeito à diversidade e a sinceridade. Tal cultura também permeou os processos que envolviam a construção do curso.

A equipe do subgrupo (ou núcleo animador) do projeto era composta por pessoas que estavam em fases de vida profissional similares e se envolveram no processo por vontade própria. Tais afinidades, somado ao histórico de trabalho com educação ambiental por todos os participantes, pode ter contribuído para que, rapidamente, emergisse o sentimento de amizade entre todos. As relações eram saudáveis e pautadas pelo cuidado com o outro e a constante autoavaliação e avaliação do processo que ocorria pelo menos semanalmente nas reuniões, o que contribuiu para manter esse espírito no grupo. Era o momento no qual cada um expressava, de forma mais direta, como estava se sentindo e o que estava achando do trabalho, como fica claro nos depoimentos inseridos como exemplos: 
Senti também a reunião muito ansiosa, diálogos estavam dispersos, com dificuldade de encaminhamentos, a captação de recursos ainda é um tabu, mais pelo nosso comprometimento dará certo" (Ata da reunião de 17/08/2016).

A formação de um grupo acolhedor, amigo, divertido, compreensivo, responsável e que não tem medo de fazer acontecer; liberdade para criar; amparo do professor Marcos (Roteiro de monitoramento. Subgrupo: Secretaria de Cursos, 2016).

Promover atividades de celebração entre o grupo, materializadas em momentos coletivos, sem pauta (como por exemplos, ida ao bar, confraternização na casa de um dos membros, lanche diferente durante a própria reunião), foi importante para evidenciar cada etapa vencida (fosse institucional ou relacionada ao aumento das matrículas que garantiam a realização do curso).

Mesmo com tais estratégias, durante os meses nos quais foi necessário lidar com poucos recursos, a incerteza da realização do curso e a criação de metas e procedimentos de trabalho geraram desconforto na maior parte das pessoas envolvidas. Acreditamos que alguns motivos para essa emergência foram: necessidade de lidar com procedimentos que ainda não estavam enraizados na cultura do grupo; limitações de recursos; grande demanda de trabalho, exigindo algumas vezes trabalho aos finais de semana ou além do que havia sido disponibilizado por cada um, como demonstram as duas avaliações sobre as dificuldades do grupo: "lidar com a ansiedade das incertezas sobre os cursos", e, também: "compreender o processo de formação constante da equipe e ter paciência com esse processo" (Roteiro de monitoramento. Subgrupo: Secretaria de Cursos, 2016).

Tais desafios foram trabalhados com esforços para que se mantivesse a máxima transparência dos processos e recursos, bem como espaços para diálogos mais profundos mesmo nas reuniões com demandas operacionais e, eventualmente, conversas individuais e apoio do coordenador do Laboratório Oca na supervisão e mediação de impasses que surgiam.

- Identidade: no tocante a identidade do grupo, percebemos que o componente da utopia é muito presente. Os estudos e resultados que temos alcançado com as pesquisas apontam nessa direção e fazem com que, constantemente, dialoguemos sobre nossos ideários. No entanto, a "louca ambição de transformar o planeta em lugar melhor pra se viver"13, justifica ações e projetos cotidianos na Oca.

O Laboratório enunciou a seguinte missão e valores no seu projeto político pedagógico:

Formação de profissionais, pesquisadores(as), cidadãos(ãs), pessoas ativas no educarse ambientalmente e no delineamento, implantação e avaliação de projetos, programas e políticas públicas de transição para sociedades sustentáveis. Participação comunitária dialógica que propicie a construção de identidades potentes para agir pelo bem comum, perseguindo cotidianamente sentidos existenciais que tornem humanos e não humanos felizes (OCA, 2016b, p. 7-8).

A identidade do subgrupo Especialização em Educação Ambiental se aproxima muito, se permeia e se funde com a do Laboratório. O trabalho em prol do Bem Comum é repetidamente lembrado, inclusive, influenciando diretamente as concepções pedagógicas do curso, na qual há um eixo intitulado Utopia, conjuntura e espiritualidade e tem como fio condutor do processo educador a realização de projetos de intervenção que atuem para transformar um território.

\footnotetext{
${ }^{13}$ Referência a uma frase recorrente que o professor Marcos Sorrentino utiliza.
} 
Para além dessa cola do grupo frente à utopia, havia o desejo de retomar os cursos de especialização a partir da expectativa de que esse tipo de processo formador seja uma ferramenta prática de realizar a missão do Laboratório Oca, o que fica claro no depoimento que avalia as fortalezas do grupo: "a materialização do sonho de realizar a especialização". (Roteiro de monitoramento. Subgrupo: Secretaria de Cursos, 2016). O registro da fala de uma participante da Oca, numa reunião para membros da equipe do subgrupo, também demonstra esse sonho coletivo: "Vocês conseguiram!! Depois de tantos anos que falamos sobre isso, que queremos...esse curso vai sair!” (Reunião para membros da equipe do subgrupo, 2016).

Outro ponto que foi muito refletido e dialogado referiu-se à aparente contradição de um laboratório de educação e política ambiental, que busca ser um lugar de resistência frente ao neoliberalismo hegemônico, realizar um curso de especialização pago numa universidade pública. Tal decisão gerou muito incômodo no subgrupo e na Oca como um todo.

Esse caminho foi escolhido num contexto no qual os cortes de recursos universitários se acentuaram. A questão que se colocava era: como viabilizar o papel de pesquisa, ensino e extensão universitária, num contexto de recessão econômica, crescimento das políticas conservadoras da universidade (por exemplo, corte de bolsas de estudos para projetos de extensão) e considerando a urgência da crise civilizatória que demanda a formação de formadores comprometidos com a transição para sociedades mais sustentáveis?

Percebemos que, para viabilizar o curso, precisaríamos ter profissionais engajados, desde monitores e coordenação pedagógica, até professores, lanche, materiais de papelaria, serviços gráficos, entre outros. Sendo que não teríamos condições de criar e manter tal estrutura com recursos financeiros via universidade, optamos pela realização de um curso pago, com algumas condicionantes.

A primeira das condicionantes era que nenhum servidor público (docente, funcionário técnico ou funcionário administrativo) receberia qualquer tipo de remuneração pelos serviços prestados. Dessa forma, coordenador geral do curso, professores e funcionários da universidade não foram remunerados pelas atividades desenvolvidas. Todos os serviços estavam inclusos nas suas horas de dedicação à universidade. Essa medida foi tomada visando dar transparência às motivações de realização do curso, ou seja, evidenciar que não há qualquer intenção de uso inapropriado da coisa pública.

Outra condicionante foi a transparência financeira dos recursos, realizada por meio do Comitê de Gestão Democrática (CGD), no qual, entre outros assuntos, são apresentados os relatórios de transparência financeira. Fazem parte desse Comitê representantes da Oca, dos professores, dos estudantes e da Secretaria de Cursos da Oca.

Outra estratégia utilizada foi o apoio da equipe gestora do curso aos estudantes que precisavam de bolsas. Foram feitos inúmeros chamados aos interessados para reuniões e outras formas de comunicação, para dialogarmos sobre como poderíamos apoiá-los a buscar patrocínio para seus estudos. Para além do apoio aos candidatos a cursistas, foram concedidas cinco bolsas de estudos, seguindo critérios que envolviam o engajamento do estudante na busca por recursos para o coletivo, e buscamos apoiar a participação de funcionários da USP e participantes da Oca que tivessem interesse.

Tais ações e reflexões deram indícios de valores e posições ideológicas da Oca e do subgrupo, que contribuem para formação da identidade do grupo.

\subsection{O processo de construção pedagógica participativa}

Neste item, apresentamos, brevemente, o processo de construção pedagógica participativa, que se deu entre o período de agosto de 2016 a fevereiro de 2017, quando ocorreu o primeiro encontro do curso. As primeiras decisões pedagógicas foram tomadas de forma mais centralizada pelos coordenadores, durante a elaboração de documentos institucionais para 
aprovação do curso na USP. Com essa estrutura, em agosto de 2016, começaram a participar do processo outros parceiros e, portanto, a partir daí, consideramos a construção pedagógica participativa.

Inicialmente, foi feito um chamado geral para a Oca se aproximar do processo, via email e através de convite em reuniões do Laboratório. Assim, foi marcado um encontro de apresentação do curso. Os interessados preencheram um formulário que solicitava informações pessoais diversas, perguntava sobre as expectativas sobre o processo, com o que gostariam de contribuir, entre outras. Após algumas reuniões com o grupo da Oca, abrimos o chamado para outros parceiros do município interessados, seguindo o mesmo procedimento via formulário. No total, vinte profissionais preencheram o formulário.

Sucederam-se algumas reuniões, visando elaborar os métodos, conteúdos, pactuar a filosofia pedagógica e o funcionamento da equipe. No segundo semestre de 2016, foram realizadas dez reuniões registradas em atas, que aconteciam com periodicidade quinzenal.

Tais reuniões possuíam uma estrutura basicamente composta por 1) acolhimento e boas vindas; 2) atividade de aquecimento/concentração/contemplação/autoconhecimento; 3) informes; 4) pautas - com o uso de diversas técnicas que fomentavam o diálogo e construção coletiva; 5) encaminhamentos; 6) avaliação individual da reunião.

Cada reunião era animada previamente, planejada e conduzida pelas coordenadoras do projeto. Em todas as reuniões foram feitas atas de registro, compartilhadas com os participantes na semana que se seguia. Essas reuniões tinham um foco mais pedagógico e contavam com a presença da equipe expandida, ou seja, em média oito profissionais, dos vinte respondentes, que tinham disponibilidade de atuar na construção incremental do curso.

Percebemos que, na maioria dos parceiros que chegavam, havia expectativa de uma construção horizontal e participativa. Isso pode ser reforçado com alguns depoimentos do formulário:

Contribuir com o processo de construção do curso da melhor forma possível, de forma participativa, pois acredito na criação coletiva e participativa de todos em busca de um bem comum, além de aprender ao mesmo tempo em que ensino (Formulário de interessado em fazer parte da equipe pedagógica do curso, 2016).

Outro formulário de interessado (2016) em integrar a equipe pedagógica do curso trouxe, como resposta à pergunta - o que você espera da equipe gestora do curso? - a seguinte afirmação: "Participação, criatividade e comunicação horizontal"

A estrutura e periodicidade das reuniões se mostraram importantes estratégias para manter a transparência e o compromisso da equipe, durante os sete meses de trabalho. Somamse às reuniões periódicas, momentos semestrais de imersão de dois dias que seguiam os mesmos princípios das demais: construção coletiva, participação, diálogo e fortalecimento do grupo.

\section{Considerações Finais}

Esta pesquisa-intervenção avança ao investigar processos de formação de profissionais atuantes no campo da educação ambiental - no início da formação do grupo - enquanto buscam, ao mesmo tempo, formar outros formadores por meio de um curso de especialização. Esse movimento evidencia a perspectiva do aprendizado pela práxis, na qual teoria, ação e reflexão acontecem concomitantemente. Após esse período de construção e planejamento inicial do Curso de Especialização Educação Ambiental e Transição para Sociedades Sustentáveis muitas outras reflexões emergiram.

As relações entre universidade pública gratuita e os cursos pagos - como ser ético / ou o que é ser ético ao construir e oferecer um processo formador transparente e acessível ao maior número de pessoas com entrada de recursos financeiros em uma universidade pública e 
gratuita? E como garantir sustentabilidade do projeto e a satisfação dos envolvidos (professores convidados, monitores, coordenadores, estudantes)? Até o momento da escrita deste artigo, avançamos na perspectiva de ter um Conselho de Gestão Democrática composto por uma diversidade de atores envolvido no curso (coordenador, professores USP e convidados, monitores, estudantes), no qual a gestão financeira é feita de forma transparente, e optamos por não oferecer retornos financeiros para funcionários públicos.

Destacamos, também, a essencialidade de conhecer os trâmites burocráticos e as perspectivas da instituição, pois isso permite que a realização do curso influencie mudanças positivas na instituição, a partir de seus princípios, diretrizes e estratégias de ensino e aprendizagem. Porém, ainda visualizamos a necessidade de continuar refletindo sobre a temática, bem como sobre a criação de novas estratégias para que, de fato, o curso contribua com a universidade pública gratuita e de qualidade e não seja apropriado por tendências neoliberais.

Em relação à concepção de educação, como viabilizar institucionalmente a emergência de processos formadores a partir de uma concepção de educação pautada pelo planejamento incremental e articulado, pela gestão democrática e participativa e pela conjuntura emergente, numa universidade que possui uma concepção de educação pautada na transmissão de conhecimento, no produtivismo científico positivista e com processos burocráticos e engessados de gestão? Optamos por enunciar cada eixo temático enquanto uma disciplina, nos dando liberdade de criação e implementação ao longo de sua execução. E gerando desafios na perspectiva de avaliação em seu sentido formal do sistema da universidade.

Nossa experiência baseia-se numa educação focada na emancipação humana, que rompe com a educação bancária, muitas vezes presente nas universidades. Porém, trata-se de um trabalho cotidiano nessa perspectiva, em especial, das estratégias de avaliação para, com responsabilidade e cuidados, fazer escolhas que nos diferenciem do produtivismo científico. Destacamos aqui, por exemplo, dois trabalhos para a conclusão do curso: projeto de intervenção e trabalho de conclusão de curso. Se olharmos para eles apenas enquanto produtos, nos aproximamos da lógica produtivista, mas ao olhar o processo de construção dos mesmos e as estratégias de ensino-aprendizagem utilizadas para sua realização é perceptível sua aproximação com a perspectiva de formação de sujeitos emancipados.

Por fim, enfatizamos a construção participativa. Quais estratégias podem contribuir para um processo de construção pedagógica participativa que valoriza o acolhimento, o cuidado, o autoconhecimento, a experiência e a autogestão, num contexto no qual as pessoas estão sempre com pressa, sobrecarregadas e tendo que cumprir metas, sejam elas profissionais ou pessoais? Encontrar o equilíbrio entre o operacional, as relações, a busca por resultados e as utopias que movem o trabalho é a base da construção participativa. Entre erros e acertos, a escolha pela autogestão contribuiu para o fortalecimento da construção participativa.

Construir a transição ou as transições para sociedades sustentáveis exige inovação e rompimento com modelos pré-existentes, que já não funcionam mais. Para tanto, acreditamos nos processos participativos e formativos para que de forma coletiva, reflexiva e crítica caminhos sejam criados. Na perspectiva de uma especialização na universidade pública, esperase que essa experiência contribua com o fortalecimento da instituição e de sua missão primeira: formar cidadãos/profissionais. Soma-se a isso a formação de pessoas capazes de atuar em diferentes áreas temáticas, partilhando o compromisso com o Bem Comum e com a construção de sociedades mais justas, democráticas, solidárias e humanas.

Talvez, a continuidade do curso e as reflexões dos participantes envolvidos possam oferecer pistas sobre essas questões e, certamente, novas perguntas irão emergir. Este trabalho pode ser aprofundado em diferentes áreas, buscando caminhar não só na criação e busca de estratégias para processos formadores, mas, especialmente, na contribuição destes para atuação na transição para sociedades mais sustentáveis e felizes. 


\section{Referencias}

ALVES, D. M. G.; SORRENTINO, M. Felicidade e espiritualidade sob um olhar transdisciplinar da educação ambiental. In: GUNTZEL-RISSATO, C.; ANDRADE, D.F.; ALVES, DMG; SORRENTINO, M; CASTELLANO, M.; PORTUGAL, S.; BRIANEZZI, T.; BATTAINI, V. (Orgs.). Educação ambiental e políticas públicas: conceitos, fundamentos e vivências. Curitiba: Appris, 2013. p. 203-214 (Vol. 1).

ALVES, D.M.G.; VIEZZER, M. Rede Planetária do Tratado de Educação Ambiental - PlanTEA. In: CONFERÊNCIA INTERNACIONAL DE EDUCAÇÃO AMBIENTAL E SUSTENTABILIDADE, 6, 2014, São Paulo. Anais... São Paulo: SESC São Paulo, 2014. p. 161-171. Disponível em: < https://sescdigitaldowloads.s3.amazonaws.com/Portal/conferenciabertioga_AF_PORTUGUES_DIGITAL_4.0_FINAL.pd f >. Acesso em 18 de jun. 2021.

ANDREWS, S. A ciência de ser feliz. São Paulo: Ágora, 2011.

BAREMBLIT, G. Compêndio de análise institucional e outras correntes. Teoria e prática. 5ed. Belo Horizonte: Instituto Félix Guatarri, 2002.

BATTAINI, V.; SORRENTINO, M. Educação ambiental local e global: políticas públicas e participação social em Fernando de Noronha. SIPS - Pedagogía Social. Revista Interuniversitária, Salamanca, n. 36, p. 49-61, 2020.

BECKER, H.S. Métodos de pesquisa em ciências sociais. São Paulo: Hucitec, 1994.

BIESTA, G. Para além da aprendizagem. Educação Democrática para um futuro humano. Tradução Rosaura Eichenberg. Belo Horizonte: Editora Autêntica, 2013 (Coleção Educação experiência e sentido).

BOLTANSKI, L.; CHIAPELLO, È. O novo espírito do capitalismo. São Paulo: Martins Fontes, 2009.

BRANDÃO, C. R. Aqui é onde eu moro, aqui nós vivemos: escritos para conhecer, pensar e praticar o município educador sustentável. 2 ed. Brasília: Ministério do Meio Ambiente, Programa Nacional de Educação Ambiental, 2005.

BRANDÃO, C. R. Aprender a saber, partilhar o saber: algumas ideias como um chão pronto para semear propostas de uma educação ambiental. In: GUNTZEL-RISSATO, C.; ANDRADE, D.F.; ALVES, D.M.G.; SORRENTINO, M.; CASTELLANO, M.; PORTUGAL, S.; BRIANEZZI, T.; BATTAINI, V. (Orgs.). Educação ambiental e políticas públicas: conceitos, fundamentos e vivências. Curitiba: Appris, 2013. p.71-87 (Vol. 1).

CASTELLS, M. O poder da identidade. São Paulo: Paz e Terra, 1999.

DALLARI, D. Direito de participação. In: SORRENTINO, M. (Org). Ambientalismo e participação na contemporaneidade. São Paulo: EDUC/FAPESP, 2002. p.92-98.

DEMO, P. Participação é conquista: noções de política social participativa. 3 ed. São Paulo: Cortez, 1996.

DENZIN, N.; LINCOLN, Y. Handbook of a qualitative research. California: Sage, 1994.

DIEGUES, A.C.S. Desenvolvimento sustentável ou sociedades sustentáveis: da crítica dos modelos aos novos paradigmas. São Paulo em Perspectiva, São Paulo, v. 6, n. 1-2, p. 22-29, 1992. 
FREIRE, P. Pedagogia da autonomia: saberes necessários à prática educativa. São Paulo: Paz e Terra, 1997.

FURTADO, C. O mito do desenvolvimento econômico. Rio de Janeiro, Paz e Terra, 1974.

GARAUDY, R. Apelo aos vivos. São Paulo: Nova Fronteira, 1981.

GERMINAR, Programa. Apostila do Curso de Formação de Facilitadores Sociais. Módulo 2:

Conhecendo a Organização e Facilitando Processos. São Paulo: EcoSocial, 2015.

HARDT, M.; NEGRI, A. Declaração: isto não é um manifesto. São Paulo: N-1 Edições, 2014.

HERCULANO, S.C. Do desenvolvimento (in)suportável à sociedade feliz. In: GOLDENBERG, M. (Coord.). Ecologia, ciência e política. Rio de Janeiro: Revan, 1992. p. 9-48.

IBGE - Instituto Brasileiro de Geografia e Estatística. Agência IBGE. Estimativas Populacionais dos municípios para 2017. Rio de Janeiro, IBGE, 2017. Disponível em:

$<$ https://agenciadenoticias.ibge.gov.br/agencia-noticias/2013-agencia-de-noticias/releases/16131-ibgedivulga-as-estimativas-populacionais-dos-municipios-para-2017.html>. Acesso em: 10 jun. 2021.

KRISHNAMURTI, J. A educação e o significado da vida. São Paulo: Cultrix, 1994.

LEFF, E. Saber ambiental. Sustentabilidade, Racionalidade, Complexidade, Poder. Petrópolis: Vozes/PNUMA, 2001.

LEFF, E. Epistemologia ambiental. Tradução de S. Valenzuela. 2 ed. São Paulo: Cortez, 2002.

MEIRA P.; SATO, M. Só os peixes não conseguem nadar contra a correnteza. Revista de Educação Pública, Cuiabá, v. 14, n. 25, p. 17-31, 2005.

MINAYO, M.C.S. Ciência, técnica e arte: o desafio da pesquisa social. In: social: teoria, método e criatividade. 19 ed. Petrópolis: Vozes, 2001. p. 9-29. . (Org.). Pesquisa

MORIN, E. Ciência com consciência. Tradução de M.D. Alexandre e M.A.S. Dória. Rio de Janeiro: Bertrand Brasil, 1996.

MORIN, E. Os setes saberes necessários à educação do futuro. São Paulo: Cortez Editora, 2014.

NEPOMUCEMO, T. Educação ambiental \& espiritualidade laica: horizontes de um diálogo iniciático. 2015. 348 f. Tese (Doutorado em Cultura, Organização e Educação) - Faculdade de Educação, Universidade de São Paulo, São Paulo, 2015.

OCA. Projeto Político Pedagógico do Laboratório de Educação e Política Ambiental. Piracicaba: Universidade de São Paulo - USP, 2016a. Disponível em:

<https://ocaesalq.files.wordpress.com/2013/07/projeto-polc3adtico-pedagc3b3gico-ppp-oca-2016.pdf〉. Acesso em: 10 jun. 2021.

OCA. O "método oca" de educação ambiental: fundamentos e estrutura incremental. Ambiente \& Educação - Revista de educação ambiental, Rio Grande, v. 21, n.1, p. 75-93, 2016 b.

RANCIÈRE, J. O mestre ignorante - cinco lições sobre emancipação intelectual. 3 ed. Belo Horizonte: Autêntica, 2015 (Coleção Educação: Experiência e Sentido). 
ROCHA, M.L.; AGUIAR, K. F. Pesquisa intervenção e a produção de novas análises. Revista Psicologia: ciência e profissão. Porto Alegre: UFRGS, 2003. p. 64-73.

RUSSELL, B. A conquista da felicidade. Rio de Janeiro: Saraiva de bolso, 2012.

SATO, M. Em busca de sociedades sustentáveis. Pátio: Revista Pedagógica, Porto Alegre, Ano 12, p. 55-59, maio/jul. 2008.

SCHAEFER, C.; VOORS, T. Desenvolvimento de iniciativas sociais: da visão inspiradora à ação transformadora. São Paulo: Antroposófica/Christophorus, 2000.

SCHUMACHER, E.F. O negócio é ser pequeno. Rio de Janeiro: Zahar, 1979.

SORRENTINO, M. 20 anos de Tblisi e cinco da Rio 92: educação ambiental no Brasil. Debates Socioambientais, São Paulo, v. 2, n. 7, p. 3-5, 1997.

SORRENTINO, M.; NASCIMENTO, E.P. do. Universidade e políticas públicas de Educação ambiental. Revista Educação em Foco, Juiz de Fora, v. 14, n. 2, p. 16-38, set.2009/Fev. 2010.

SORRENTINO, M.; PORTUGAL, S.; PAZOS, A.S.P.; VÁZQUES, C.V. Por uma nueva cultura de la tierra, Tierra y território: rutas de transición para sociedades sustentables. Carpeta Informativa del CENEAM - Centro Nacional de Educación Ambiental, Segovia, p.1-7, abril/2020. Disponível em: https://www.miteco.gob.es/es/ceneam/carpeta-informativa-del-ceneam/numeros-anteriores/carpetaabril2020_tcm30-508381.pdf. Acesso em 18 de jun. 2021.

SORRENTINO, M.; SIM, E.F.C.; SACCONI, et al. Comunidade, identidade, diálogo, potência de ação e felicidade: fundamentos para educação ambiental. In: GUNTZEL-RISSATO, C.; ANDRADE, D.F.; ALVES, D.M.G. (Orgs.). Educação ambiental e políticas públicas: conceitos, fundamentos e vivências Curitiba: Appris, 2013. p. 21-62 (Vol. 1).

SORRENTINO, M.; CASTELLANO, M.; PORTUGAL, S.; BRIANEZZI, T.; BATTAINI, V. (Orgs.). Educação ambiental e políticas públicas: conceitos, fundamentos e vivências. Curitiba: Appris, 2013. p. 21-62 (Vol. 1).

SORRENTINO, M.; PORTUGAL, S. Educação Ambiental e a Base Nacional Comum Curricular. Relatório Analítico. 2015. Disponível em: http://ixfbeaivecea.unifebe.edu.br/wiew/information/downloads-consulta-publica/3.pdf .Acesso em: 18 de jun. de 2021.

TASSARA, E. T. O.; ARDANS, O. Participação emancipatória: reflexões sobre a mudança social na complexidade contemporânea. In: GÜTZEL-RISSATO, C.; ANDRADE, D. F.; ALVES, D. M. G. et al. (Orgs.) Educação Ambiental e Políticas Públicas: Conceitos, Fundamentos e Vivências. Curitiba: Appris, 2013. p.281 -294 (Vol. 1).

TRATADO de educação ambiental para sociedades sustentáveis e responsabilidade global. Brasília: MEC/SECAD, 1997. Disponível em:

<http://portal.mec.gov.br/secad/arquivos/pdf/educacaoambiental/tratado.pdf>. Acesso em 10 jun. 2021.

VIEZZER, M. Somos todos aprendizes: lembranças da construção do Tratado de Educação Ambiental. 2004. Disponível em: < https://tratadodeea.blogspot.com/2008/06/somos-todos-aprendizes-lembranasda.html >. Acesso em: 18 de jun. 2021. 